\title{
Economic Impact and Cost Benefit of the Inpatient Clinical Pharmacist Interventions in Cancer Care Units
}

\section{Dina Abushanab}

Hamad Medical Corporation

Amaal Gulied

Hamad Medical Corporation

Anas Hamad

Hamad Medical Corporation

Palli Valappila Abdul Rouf

Hamad Medical Corporation

Moza Al Hail

Hamad Medical Corporation

Wessam El Kassem

Hamad Medical Corporation

Maguy El Hajj

Qatar University College of Pharmacy

Daoud Al-Badriyeh ( $\nabla$ daoud.a@qu.edu.qa )

Qatar University https://orcid.org/0000-0001-7791-954X

\section{Research Article}

Keywords: Clinical pharmacist intervention, cancer, economic benefit, cost-benefit, cost saving, cost avoidance, adverse drug event

Posted Date: January 4th, 2022

DOI: https://doi.org/10.21203/rs.3.rs-1180212/v1

License: (c) (i) This work is licensed under a Creative Commons Attribution 4.0 International License.

Read Full License 


\section{Title page}

Title:

Economic impact and cost benefit of the inpatient clinical pharmacist interventions in cancer care units

\section{Authors}

Dina Abushanab ${ }^{1}$, Amaal Gulied ${ }^{2}$, Anas Hamad ${ }^{2}$, Palli Valappila Abdul Rouf ${ }^{1}$, Moza Al Hail ${ }^{1}$, Wessam ElKassem $^{1}$, Maguy Saffouh El Hajj ${ }^{3}$, Daoud Al-Badriyeh ${ }^{3}$

\section{Affiliations}

${ }^{1}$ Pharmacy Department, Hamad Bin Khalifa Medical City, Hamad Medical Corporation, Doha, Qatar

${ }^{2}$ Pharmacy Department, National Center for Cancer Care \& Research, Hamad Medical Corporation, Doha, Qatar

${ }^{3}$ College of Pharmacy, QU Health, Qatar University, Doha, Qatar

\section{Corresponding author:}

Daoud Al-Badriyeh, PhD, Health Economics and Outcomes Research, College of Pharmacy, QU Health, Qatar University, Doha 2713, Qatar. Tel: +974 4403 5591. Fax: +974 4403 5551. Email: daoud.a@qu.edu.qa. ORCID: https://orcid.org/0000-0001-7791-954X

Number of words (manuscript): 3,410

Number of words (abstract): 248 


\section{Abstract}

2 Background: Clinical pharmacists play a key role in ensuring the optimum use of cancer medicines. Yet,

3 the economic benefit of this role has never been assessed in Qatar.

4 Aim: To evaluate the overall economic impact of clinical pharmacist interventions in the main cancer care 5 setting in Qatar.

6 Methods: From the public healthcare perspective, this was an analysis of the total economic benefit and

7 a cost-benefit analysis of the clinical pharmacy interventions. As a study sample size, patient records in 8 March 2018, July/August 2018, and January 2019 were retrospectively reviewed at the National Center 9 for Cancer Care \& Research (NCCCR), Qatar. The total benefit from interventions was the total of the cost 10 avoidance due to preventable adverse drug events (ADEs) plus the cost savings associated with 11 therapeutic interventions. The interventions cost was based on salary and increased cost due to 12 therapeutic interventions. The cost-benefit analysis results were presented via net benefit and benefit13 to-cost ratio measures.

14 Results: Total of 1,352 interventions occurred during the 3-month follow-up period. The total benefit was QAR 196,010,360 (USD53,834,206), constituting cost avoidance of QAR 194,764,534 (USD 53,492,040) and cost savings of QAR $1,245,826$ (USD 342,166), mostly due to recommending additional medications

17 and the medication dose reduction. The benefit-to-cost ratio was 174:1 and the annual net benefit was 18 QAR 779,539,440 (USD 214,100,351). Sensitivity analyses confirmed the robustness of results.

19 Conclusion: The clinical pharmacist intervention is a cost-beneficial practice in the NCCCR setting, 20 associated with ADEs prevention and substantial economic benefits, including relative to the interventions 21 cost.

22 Keywords: Clinical pharmacist intervention, cancer, economic benefit, cost-benefit, cost saving, cost avoidance, adverse drug event 
26

27

28

29

30

31

32

33

34

35

36

37

38

39

40

41

42

43

44

- The clinical interventions performed by clinical pharmacists successfully prevent adverse drug events (ADEs) that are associated with substantial net benefit, adding to QAR 779,539,440 (USD $214,100,351$ ) per year, with an associated long-term return to investment at a rate of 174:1.

- Our results suggest that the intervention role of clinical pharmacists should be expanded, given that the majority of interventions prevented ADEs, generating cost savings. Also demonstrated, in parallel to the clinical pharmacist interventions, is the potential need for continuous education on cancer therapies and an improved implantation of clinical pathways.

(3)

4

5

6

7

8


46 The irrational use of medication is a foremost worldwide public health problem, with a considerable

47 impact on clinical, humanistic, and economic outcomes [1]. The World Health Organization estimated that

48 over $50 \%$ of all medications are associated with drug-related problems (DRPs), which is described as 'an

49 event including drug therapy which can actually and potentially interfere with optimal health outcomes'

$50[2-4]$

51 Managing cancer patients is complex, and patients are more susceptible to developing DRPs due to

52 narrow therapeutic index of some cancer medications with a high incidence of toxicity[5,6]. Drug-disease

53 and drug-drug interactions among chemotherapy agents and daily treatments, or adjuvant regimens, may

54 also cause severe adverse drug events (ADEs), defined as 'injuries resulting from the use of a drug' [4],

55 and extend hospital stay with a substantial economic burden [7].

56 The pharmacist role has grown substantially from primarily focusing on the operational activities of the

57 pharmacy profession to being involved in direct patient care[7]. The clinical pharmacist intervention is

58 one of the most critical approaches used to avoid ADEs in practices. The actions developed by the clinical

59 pharmacists through reviewing medication orders and intervening when needed are tremendously

60 significant. These actions include but are not limited to identifying and managing DRPs, ensuring better

61 utilization of medications, to eventually reduce the risk of unfavorable ADEs, which in turn reduces the

62 healthcare costs [8]. Indeed, previous studies reporting pharmacists' participation in the cancer setting

63 have demonstrated improved quality of care [9-11]. However, recruiting clinical pharmacists as well as

64 implementing the interventions themselves can come with added costs that may offset any cost savings

65 produced by the prevention of ADEs.

66

67 Aim 
68 In this study, therefore, we sought to perform a first-time evaluation of the economic impact and cost-

69 benefit of the clinical pharmacist interventions for DRPs in the cancer care units at the National Center for

70 Cancer Care and Research (NCCCR) in Qatar.

71

\section{Ethics approval}

73 The study was approved by the Medical Research Center, HMC (MRC-01-19-110).

74

75

Methods

76

\section{Study setting}

77 The study was conducted at the NCCCR in Hamad Medical Corporation (HMC), the main provider of 78 secondary and tertiary healthcare in Qatar. NCCCR is the leading cancer hospital in Qatar, with 91 beds, 79 and it offers a range of specialized services [12].

\section{Study design}

81 The study is a retrospective review of clinical pharmacist interventions, defined as any action by a

82 pharmacist that directly resulted in a change to patient management or therapy [13]. All clinical

83 interventions were directly obtained via the clinical intervention sheet, which is included in each patient

84 record in the Cerner electronic medical database. When relevant data was not found in the clinical

85 intervention sheet, data was directly obtained from the Cerner medical record of the patient.

\section{Study population}

87 The targeted clinical pharmacist interventions in this study were based on those performed in patients 88 admitted to the inpatient wards in the oncology, hematology, urgent care, and palliative care units. The 
89 study sample was based on interventions that occurred among hospitalized patients in inpatient wards

90 during a 3-month sample size period (in March 2018, from July 15 to August 15, 2018, and in January

91 2019).

92 Inclusion criteria:

- Clinical pharmacist interventions during a 3 month follow-up period (in March 2018, from July 15 to August 15, 2018, and in January 2019).

- All the interventions that were performed by clinical pharmacists or clinical pharmacist specialists.

- All interventional recommendations to physicians that were based on evidence. To note, clinical pharmacists have to include evidence in support of their interventions for consideration by physicians before approving the interventions.

- The interventional recommendations that were accepted by the physicians.

Exclusion criteria:

- Interventions documented by the operational pharmacists.

\section{Outcome}

103 The main outcome of this study was to evaluate the cost-benefit of preventable ADEs through 104 interventions by clinical pharmacists. Preventable ADEs occur due to a medication error that reaches the 105 patient and result in any degree of harm [14]. The 'cost' is defined as the cost of hiring the clinical 106 pharmacist as well as any increase in the cost of the course of therapy because of an intervention. The 107 'benefit' is the economic value of ADEs avoided because of interventions as well as any decrease in the 108 cost of the course of therapy because of an intervention. 
111 The cost of the intervention was calculated based on the sum of the salary of clinical pharmacists, added

112 to any increased cost of therapy associated with the administration of intervention. The basic monthly

113 salary of a clinical pharmacy in Qatar is estimated to be around QAR20,000 (USD5,493). For the current

114 study, however, calculations were based on an overestimated monthly salary of QAR30,000 (USD8,239).

115 Details of the cost of interventions calculations can be seen in Supplementary Information S1. As per the 116 duration of study follow up, the cost of intervention over 3 months was calculated.

\section{Cost savings}

118 Cost savings based on the clinical pharmacist interventions were the reduced cost of therapy associated 119 with therapy changes due to the intervention. Details of the cost savings calculations can be seen in 120 Supplementary Information S1. As per the duration of study follow up, the cost saving over 3 months was 121 calculated.

\section{Cost avoidance}

123 Cost avoidance was the cost avoided by eliminating the occurrence of ADEs as a consequence of the 124 clinical pharmacist interventions [15]. Based on the method of Nesbit et al., the likelihood of an ADE in 125 the absence of the intervention was determined at 0 (none), 0.01 (very low), 0.1 (low), 0.4 (medium), or 1260.6 (high). The description of Nesbit et al. method is shown in Supplementary Information S2. The cost of 127 an ADE was calculated based on the conservative assumption that an ADE will lead to an additional 2 days 128 of hospital stay in the relevant unit, which is consistent with previous studies [16]. Further details of the 129 cost avoidance calculations can be seen in Supplementary Information S1. As per the duration of study 130 follow up, the cost avoidance over 3 months was calculated. 
132 Results of the cost-benefit analysis were presented in terms of the total benefit, the benefit-to-cost ratio,

133 and the net benefit of the intervention, which was calculated in 3-monthly and annual values. Cost is the

134 cost of the interventions, while the total monetary value of the benefit of the interventions was calculated

135 as the sum of the cost savings and the cost avoidance associated with the interventions.

\section{Expert panel}

137 In accordance with the Nesbit et al. method, an expert panel was used to identify the probabilities of ADEs

138 in the absence of interventions [15]. The panel was of four clinical pharmacists who have over 5 years of

139 clinical experience in the area of cancer and its therapies, whereby each provided an estimate of the

140 likelihood of an ADE in the absence of an intervention. The average ADE probability in the absence of each

141 of the interventions was calculated.

\section{Perspective}

143 The study was conducted from the perspective of the public NCCCR hospital. Thus, only direct medical 144 costs were considered in the analysis.

\section{Cost inputs}

146 The monetary values of resources were calculated, where the cost of medications, non-medication-based

147 resources such as laboratory and diagnostic tests, and hospital stay were obtained via the pharmacy and 148 the finance and costing departments at HMC. The salary values of clinical pharmacists and clinical 149 pharmacy specialists were derived from the human resources of HMC. All costs were adjusted to the 150 financial year 2021, utilizing the Qatari health Consumer Price Index [17], and were presented in Qatari 151 Riyal (QAR) and the United States Dollar (USD).

\section{Sample size}


153 All clinical pharmacist interventions documented during the 3-month follow-up period of the study were 154 included in the analysis. This study is not comparative and there are no relevant sample size calculations 155 for the purpose of analysis. There is also no standardization in relation to the sample size used in similar 156 literature studies as this is based on a variety of factors, including size of setting and prevalence of the 157 underlying conditions. Unlike clinical research, economic evaluations like the current one are not 158 concerned with hypothesis testing, but they are about making a cost estimation. Here, even if an 159 economic evaluation is underpowered, it still provides important information that guides decision making 160 [18-20].

161 To enhance how representative the sample size of the population is, the sample size was based on the 162 first month after the annual staff performance evaluation in NCCCR, the last month in the year before the 163 annual performance evaluation, and the middle month of the year. This is as it is always possible that how 164 vigilant pharmacists are and the prevalence of interventions by clinical pharmacists are affected during 165 the institutional review process of the performance of the clinical pharmacists. There is no evidence of 166 such a pattern in the clinical pharmacy practices, and this sampling is only precautionary.

\section{Statistical Analysis}

168 Data were tabulated for each patient and analyzed using the IBM SPSS (Statistical Package for the Social

169 Sciences) version-24. The data were presented as numerical and percentage measures for categorical 170 variables and as mean and standard deviation measures for continuous variables. Kruskal-Wallis and Chi171 Square tests were used to detect any significant differences among the three sample size groups, i.e. 172 March 2018, July/August 2018, and January 2019.

\section{Sensitivity analysis}


174 One-way and multivariate sensitivity analyses were used to assess the impact of uncertainty in the base-

175 case values of variables in relation to the costs and ADEs probabilities, to enhance the 176 robustness/generalizability of the study conclusion.

177 One-way sensitivity analysis was performed to target values of individual uncertain input variables to 178 analyze the effect of uncertainty on the study conclusion. Targeted uncertain inputs included the clinical 179 pharmacist salary and the cost of the ADE, using an assigned $\pm 20 \%$ uncertainty range.

180 Multivariate uncertainty analysis was performed by targeting several underlying uncertain probabilistic

181 inputs in the economic model before re-running the model several times, for a distribution of the model

182 results to be generated. Here, the probabilistic inputs of interest were the probabilities of the avoided 183 ADEs set by the expert panel, using an assigned $\pm 15 \%$ uncertainty range for any probability.

184 Both sensitivity analyses were conducted via Monte Carlo simulation (1000 iterations), using @Risk-5.7 185 (Palisade Corporation, NY).

\section{Results}

\section{Characteristics of patients and interventions}

189 A total of 1,352 interventions in 1,352 patients occurred during the study follow-up period. The mean 190 patient age was 47 years. Among the study population, 59.39\% were male. Interventions that were related 191 to oncology comprised majority of interventions (73.52\%), followed by hematology interventions 192 (15.31\%).

193 Overall, as per the categorization of interventions in the patient clinical intervention sheet, the most 194 common interventions by the clinical pharmacists were related to the appropriateness of therapy (78.1\%), 
195 followed by interventions related to dosing and administration (16.2\%), contraindication and safety

196 (3.18\%), drug interaction (1.48\%), and duplicate therapy (1.04\%).

197 There were no significant differences between the study groups except with regards to the ward type 198 (Table 1).

199 Supplementary Information S3 presents a summary of the categories of the interventions types, including 200 study examples, and the associated average probability of avoided ADEs as per category.

201 Economic analysis

202 Cost of intervention

203 Based on interventions performed in the current study, a clinical pharmacist performed an average of 250 204 interventions over the 3-month study period. Based on total number of interventions in the current study, 2056 clinical pharmacists were needed, where the overall salary of the clinical pharmacists was calculated to 206 be QAR180,000 (USD49,437). For the added cost associated with therapeutic interventions for the DRPs 207 over a 3-month period, this was QAR945,500 (USD259,681). The total cost of the intervention over the 3208 month study period is, therefore, adding to QAR1,125,500 (USD309,118). The added cost with 209 interventions as per different intervention type categories can be seen in Table 2.

210 Cost saving

211 The overall cost saving was QAR1,245,826 (USD 342,166). Cost saving as per different intervention type 212 categories can be seen in Table 2.

213 Cost avoidance

214 An average probability of 0.03 was calculated for each of 3 interventions, an average of 0.1 was calculated 215 for each of 541 interventions, an average of 0.2 was calculated for each of 406 interventions, an average 216 of 0.3 for each of 347 interventions, an average of 0.4 for each of 46 interventions, and an average of 0.5 217 is the estimated probability with each of 9 interventions. The overall cost avoidance due to the 
218 interventions over a 3-month period was QAR194,764,534 (USD53,492,040). Table 2 summarizes cost

219 avoidance associated with each type of intervention category.

220 Cost-benefit analysis

221 The total benefit due to the interventions over a 3-month period was QAR196,010,360 (USD 53,834,206).

222 The benefit-to-cost ratio was 174:1, where for every QAR1 (USD0.27) invested into the clinical pharmacist

223 interventions approach, a QAR174 (USD48) of benefit is generated. The net benefit was QAR 194,884,860

224 (USD53,525,089) per 3 months and QAR779,539,440 (USD214,100,351) per 1 year of intervention

225 practices. Overall costs and cost-benefit calculations are summarized in Table 3.

\section{Sensitivity analysis}

227 The outcome of the economic model was insensitive to uncertainty in the clinical pharmacist salary and 228 in the cost of the ADE.

229 Multivariate sensitivity analysis demonstrated that there is a $100 \%$ probability that the pharmacist 230 intervention is associated with positive a 3-monthly net benefit and total benefit (Fig.1a) and an annual 231 net benefit (Fig. 1b). Furthermore, as illustrated in Fig. 1c, the analysis showed that there is a 100\% 232 probability that the pharmacist intervention is associated with an $>1$ benefit to cost ratio.

233 Input uncertainties and sampling distributions used in the one-way and multivariate sensitivity analyses, 234 and the details of their outcomes, are shown in Table 4.

235 A regression Tornado analysis revealed that the main driver of the outcome was the cost of ADE, followed 236 by the 0.3 probability of avoided ADE (Fig. 2). 
This study was conducted for the purpose of evaluating the cost-benefit of managing DRPs of cancer units at NCCCR for the prevention of ADEs among hospitalized cancer patients in Qatar. This is the first costbenefit study of clinical pharmacist interventions in Qatar. Our study revealed that clinical pharmacist

242 interventions could significantly reduce the incidence of ADEs, which may result in a net benefit of 243 QAR779,539,440 (USD214,100,351). The majority of the DRPs were related to the appropriateness of 244 therapy, followed by DRPs related to dosing and administration.

245 Apart from the economic impact of cancer pharmacy interventions in optimizing outpatient practices, 246 there are few published studies on the economic impact of clinical pharmacy interventions in the inpatient 247 clinical cancer setting. Gregori et al. recently suggested that the total cost saving of inpatient cancer 248 pharmacy interventions contributed to $€ 175,563$ for a total of 1,970 interventions, corresponding to an 249 average cost avoidance of $€ 390,480$. Similar to our results, the cost of ADE was the key driver affecting 250 the outcome [9]. This study, however, was prospective and only included oncology and hematology 251 interventions among patients receiving first injectable chemotherapy and/or immunotherapy regimen. 252 Also different from our study, in the retrospective study by Zecchini et al., the cost saving of inpatient 253 cancer pharmacy interventions was only evaluated for injectable cancer medications, which led to $254 € 15,096$ for a total of 237 interventions, limited relative to results in our study where we evaluated all 255 cancer medications regardless of the antineoplastic dosage form [10]. In a prospective, pilot study at an 256 inpatient ambulatory oncology unit in the United States, by Randolph et al., only the cost avoidance of 257 DRPs was evaluated, calculating an annual cost avoidance of USD282,741 per pharmacist, resulting in a 258 net benefit of USD138,441 (19).

259 The probability of preventable ADE was determined using the Nesbit et al. method, which provides the 260 best source to estimate the probability of avoidable ADEs $[15,16,18,19,21]$, which was based on average 261 scores provided by the four clinical pharmacists. Most of the estimated probability scores were low, which 262 is consistent with relevant literature studies adopting the same methods $[19,22,23]$. 
263 The estimated cost saving was calculated conservatively based on the 90-day prescription refills cost of

264 the intervened chronic medications and as per the prescriber order or the local protocol for acute medical

265 conditions. Regardless of the DRPs and how they vary in severity and duration, they are uniformly

266 compared based on the value of the ADEs associated with them. While the literature reported that ADEs

267 might cause more than two days of hospital admission (i.e. 4.6 days) [23], the estimated cost avoidance

268 was calculated conservatively by considering only two additional days of hospital stay if ADEs occurred.

269 Considering longer hospital stays in the current study will only further increase the economic benefit of

270 the interventions.

271 In agreement with one previous study [24], the most frequent type of DRPs intercepted by clinical

272 pharmacists was related to inappropriate therapy, which made $78 \%$ of interventions. The addition of

273 another medication and decreasing medication doses were the main resource use changes that resulted

274 in cost saving and cost avoidance. The dose of most antineoplastic drugs is mainly based on the calculated

275 body surface area, which should be recalculated based on weight change. This may be missed by

276 physicians [25].Another example was related to adding antiemetics to prevent chemotherapy-induced

277 nausea and vomiting, which remain the main issue for many cancer patients [26]. Also an example is the

278 leucovorin rescue, which was added to all patients receiving the high dose methotrexate to prevent

279 toxicity [27].

280 Our study demonstrated the importance of individualized therapy, especially in relation to the adjustment

281 of dose. Some of our study population is comprised of critically ill patients where the incidence of renal

282 disease is frequently high, and the dose adjustment of medications is required [28]. This type of

283 intervention resulted in a total cost saving of QAR22,088 (USD6,066) and cost avoidance of

284 QAR23,772,983 (USD652,924). 
Discontinuation of inappropriate or unnecessary medicine also comprised a high percentage ( $22 \%)$ of interventions. It led to cost saving of QAR364,987 (USD100,243) and a cost avoidance of QAR 180,101,227 (USD49,464,783). This is consistent with the literature, where, for example, LaPointe et al. showed over $35 \%$ of interventions to be due to wrong medications [29].

Clinical pharmacists also play an important role in disease-related problems. Indeed, the deployment of clinical pharmacists in clinical rounds led in our study to recommend interventions related to laboratory testing such as therapeutic drug monitoring, diagnostic, and culture tests, which resulted in a cost saving of QAR23,807 (USD6,539) and a cost avoidance of QAR45,025,307 (USD12,366,192).

This study is not without limitations. The cost-benefit might be over or underestimated due to the nature of the retrospective study design, which has the inherent limitation of missing data, especially as daily reporting of interventions is not mandatory. Furthermore, the clinical outcome of patients, wherein clinical pharmacists intervened, were only analyzed using the probabilities of avoidable ADEs, which may 297 not reflect the real impact of interventions beyond the ADEs. In addition, the cost of ADEs was calculated 298 with the assumption that it is equal among the different ADEs, universally associated with an additional two days of hospital stay. As already discussed in methods, however, this is justified, especially since it is 300 impossible to follow up patients until the end of intervention consequences that never took place. Also, 301 in our study, a 3-month follow-up duration may not accurately represent the real economic benefits over 302 one year. However, given how the 3-month follow up was selected as a sample size, as already discussed 303 above, and given the lack of significant differences in patient characteristics between the 3 months of the 304 follow-up duration, there is no reason to assume that the remaining months of the year will differ and 305 that results from the study's 3-month follow-up cannot be extrapolated to calculate an annual benefit. 306 Finally, while the comprehensive one-way and multivariate sensitivity analyses performed would 307 considerably increase the robustness and generalizability of results beyond the study setting, our results 
308 will need to be considered with caution by other settings, given that the resource utilization and costs can

309 considerably differ.

310 Given that the NCCCR is only one of several specialized hospitals under the HMC in Qatar, among which

311 the nature and quantity of interventions considerably vary, similar evaluations to the current one would

312 ideally be also required to better understand the impact of the pharmacy interventions in the different

313 HMC inpatient clinical settings.

315 Conclusion

316 Based on the study assumptions and setting, the clinical interventions performed by clinical pharmacists

317 successfully prevent ADEs that are associated with substantial net benefit with an associated long-term

318 return to investment. These results suggest that the intervention role of clinical pharmacists should be

319 expanded, given that the majority of interventions prevented ADEs, generating cost savings. Also

320 demonstrated, in parallel to the clinical pharmacist interventions, is the potential need for continuous

321 education on cancer therapies and an improved implantation of clinical pathways.

322 
324 1. le Grand A, Hogerzeil H V, Haaijer-Ruskamp FM. Intervention research in rational use of drugs: a 325 review. Health Policy Plan. England; 1999;14:89-102. https://doi10.1093/heapol/14.2.89

326 2. Foroughinia F, Tazarehie SR, Petramfar P. Detecting and managing drug-related problems in the 327 neurology ward of a tertiary care teaching hospital in Iran: A clinical pharmacist's intervention. J Res 328 Pharm Pract. 2016;5:285-9. https://doi10.4103/2279-042X.192455

329 3. Genebra. World Health Organization (WHO). The role of education in the rational use of medication. 3302006.

331 4. Bailey C, Peddie D, Wickham ME, et al. Adverse drug event reporting systems: a systematic review. $\mathrm{Br}$ 332 J Clin Pharmacol. 2016;82:17-29. https://doi10.1111/bcp.12944

333 5. Chopra D, Rehan HS, Sharma V, et al. Chemotherapy-induced adverse drug reactions in oncology 334 patients: A prospective observational survey. Indian J Med Paediatr Oncol Off J Indian Soc Med 335 Paediatr Oncol. 2016;37:42-6. https://doi10.4103/0971-5851.177015

336 6. Monestime S, Page R, Jordan WM, et al. Prevalence and predictors of patients reporting adverse drug 337 reactions to health care providers during oral targeted cancer treatment. J Am Pharm Assoc.

338 2021;61:53-9. https://doihttps://doi.org/10.1016/j.japh.2020.09.001

339 7. Blouin RA, Adams ML. The Role of the Pharmacist in Health Care: Expanding and Evolving. N C Med J. 340 United States; 2017;78:165-7. https://doi10.18043/ncm.78.3.165

341 8. Al-Qudah RA, Al-Badriyeh D, Al-Ali FM, et al. Cost-benefit analysis of clinical pharmacist intervention 342 in preventing adverse drug events in the general chronic diseases outpatients. J Eval Clin Pract. England; $343 \quad$ 2020;26:115-24. https://doi10.1111/jep.13209

344 9. de Grégori J, Pistre $\mathrm{P}$, Boutet $\mathrm{M}$, et al. Clinical and economic impact of pharmacist interventions in an 
ambulatory hematology-oncology department. J Oncol Pharm Pract Off Publ Int Soc Oncol Pharm

Pract. England; 2020;26:1172-9. https://doi10.1177/1078155220915763

10. Zecchini C, Vo T-H, Chanoine S, et al. Clinical, economic and organizational impact of pharmacist

348 interventions on injectable antineoplastic prescriptions: a prospective observational study. BMC Health Serv Res. 2020;20:113. https://doi10.1186/s12913-020-4963-7

11. Delpeuch A, Leveque D, Gourieux B, et al. Impact of clinical pharmacy services in a hematology/oncology inpatient setting. Anticancer Res. Greece; 2015;35:457-60.

12. Mohsen $\mathrm{H}$, Haddad $\mathrm{P}$, Allam A, et al. Patterns in place of cancer death in the State of Qatar: a population-based study. PLoS One. Public Library of Science; 2014;9:e109615-e109615. https://doi10.1371/journal.pone.0109615

13. Dooley MJ, Allen KM, Doecke CJ, et al. A prospective multicentre study of pharmacist initiated changes to drug therapy and patient management in acute care government funded hospitals. Br J Clin

357 Pharmacol. 2004;57:513-21. https://doi10.1046/j.1365-2125.2003.02029.x

14. Garrouste-Orgeas M, Philippart F, Bruel C, et al. Overview of medical errors and adverse events. Ann Intensive Care. Springer; 2012;2:2. https://doi10.1186/2110-5820-2-2

15. Nesbit TW, Shermock KM, Bobek MB, et al. Implementation and pharmacoeconomic analysis of a 361 clinical staff pharmacist practice model. Am J Heal Pharm AJHP Off J Am Soc Heal Pharm. England; 2001;58:784-90. https://doi10.1093/ajhp/58.9.784

16. Chen C-C, Hsiao F-Y, Shen L-J, et al. The cost-saving effect and prevention of medication errors by

364 clinical pharmacist intervention in a nephrology unit. Medicine (Baltimore). 2017;96:e7883.

365 https://doi10.1097/MD.0000000000007883

17. Qatar Inflation Rate. 2021. Available from: https://tradingeconomics.com/qatar/inflation-cpi. 
18. Sebaaly J, Parsons LB, Pilch NAW, et al. Clinical and Financial Impact of Pharmacist Involvement in

369 Discharge Medication Reconciliation at an Academic Medical Center: A Prospective Pilot Study. Hosp

370 Pharm. 2015;50:505-13. https://doi10.1310/hpj5006-505

371 19. Gallagher J, Byrne S, Woods N, et al. Cost-outcome description of clinical pharmacist interventions in

372 a university teaching hospital. BMC Health Serv Res. 2014;14:177. https://doi10.1186/1472-6963-14-

$373 \quad 177$

374 20. Branham AR, Katz AJ, Moose JS, et al. Retrospective analysis of estimated cost avoidance following

375 pharmacist-provided medication therapy management services. J Pharm Pract. United States;

376 2013;26:420-7. https://doi10.1177/0897190012465992

377 21. Hirsch JD, Bounthavong M, Arjmand A, et al. Estimated Cost-Effectiveness, Cost Benefit, and Risk

378 Reduction Associated with an Endocrinologist-Pharmacist Diabetes Intense Medical Management

379 “Tune-Up" Clinic. J Manag care Spec Pharm. United States; 2017;23:318-26.

380 https://doi10.18553/jmcp.2017.23.3.318

381 22. Han J-M, Ah Y-M, Suh SY, et al. Clinical and economic impact of pharmacists' intervention in a large

382 volume chemotherapy preparation unit. Int J Clin Pharm. Netherlands; 2016;38:1124-32.

383 https://doi10.1007/s11096-016-0339-9

384 23. Bates DW, Spell N, Cullen DJ, et al. The costs of adverse drug events in hospitalized patients. Adverse 385 Drug Events Prevention Study Group. JAMA. United States; 1997;277:307-11.

386 24. Allard J, Carthey J, Cope J, et al. Medication errors: causes, prevention and reduction. Br J Haematol. 387 England; 2002;116:255-65. https://doi10.1046/j.1365-2141.2002.03272.

388 25. Body surface area for adjustment of drug dose. Drug Ther Bull [Internet]. 2010;48:33 LP - 36. 
389 Available from: http://dtb.bmj.com/content/48/3/33.abstracthttps://doi10.1136/dtb.2010.01.0002

390 26. Gupta K, Walton R, Kataria SP. Chemotherapy-Induced Nausea and Vomiting: Pathogenesis,

391 Recommendations, and New Trends. Cancer Treat Res Commun. 2021;26:100278.

392 https://doi.org/10.1016/j.ctarc.2020.100278

393 27. Howard SC, McCormick J, Pui C-H, et al. Preventing and Managing Toxicities of High-Dose

394 Methotrexate. Oncologist. 2016/08/05. AlphaMed Press; 2016;21:1471-82.

395 https://doi10.1634/theoncologist.2015-0164

396 28. Wilkins RG, Faragher EB. Acute renal failure in an intensive care unit: incidence, prediction and

397 outcome. Anaesthesia. England; 1983;38:628-34. https://doi10.1111/j.1365-2044.1983.tb12153.x

398 29. LaPointe NMA, Jollis JG. Medication errors in hospitalized cardiovascular patients. Arch Intern Med.

399 United States; 2003;163:1461-6. https://doi10.1001/archinte.163.12.1461

400

401

402

403

404

405

406

407

408 

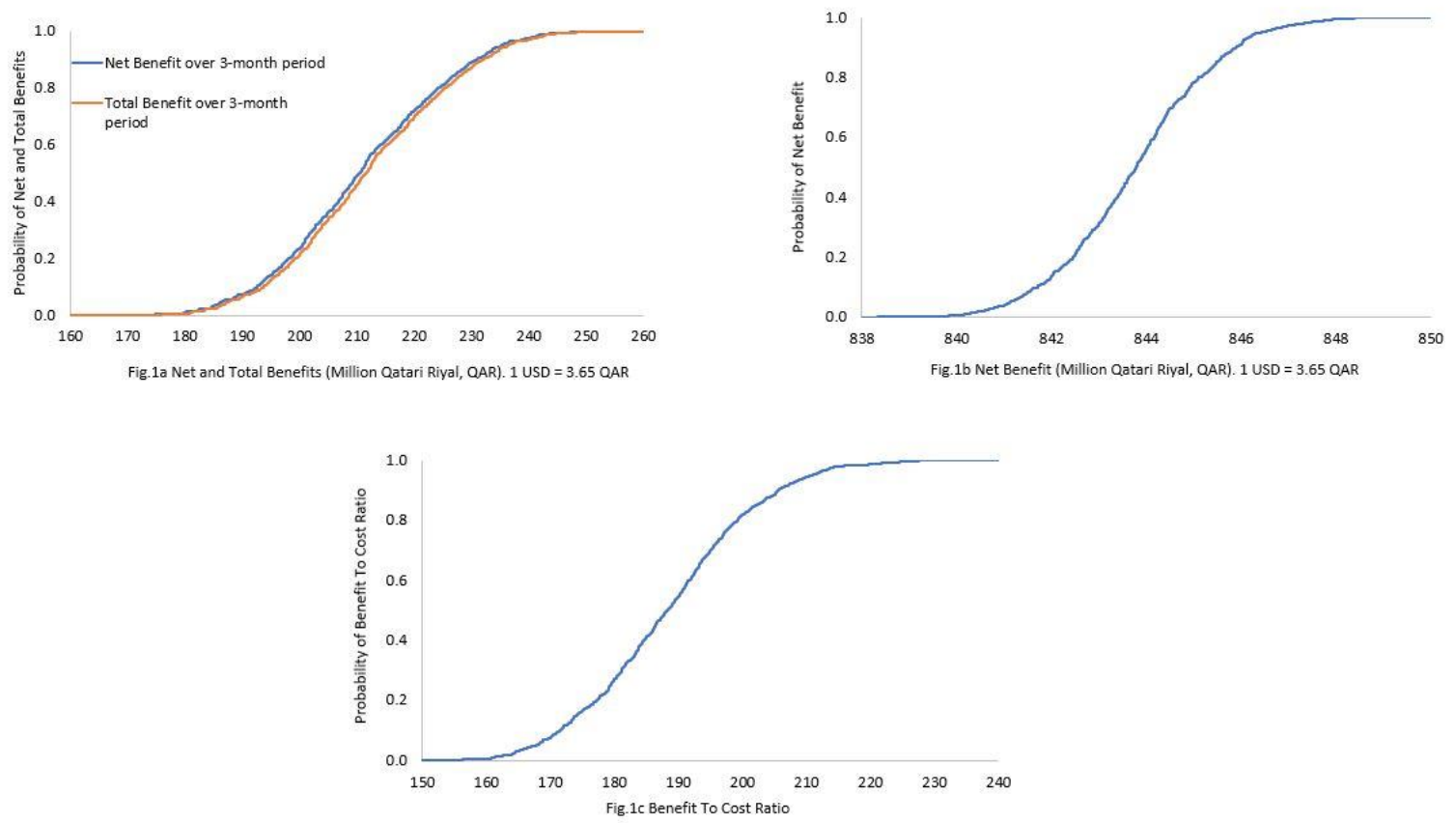

412 Figure 1. Probability curves of economic impact results

Cost of adverse drug event (ADE)

0.3 probability of avoided $A D E$

0.2 probability of avoided $A D E$

0.1 probability of avoided ADE

0.4 probability of avoided ADE

0.5 probability of avoided $A D E$

0.03 probability of avoided $A D E$ 
417 Table 1. Patients' demographics among the study periods

\begin{tabular}{|c|c|c|c|c|c|}
\hline & & $\begin{array}{l}\text { March } 2018 \\
(n=463)\end{array}$ & $\begin{array}{l}\text { July-August } 2018 \\
(n=309)\end{array}$ & $\begin{array}{l}\text { January } 2019 \\
(n=580)\end{array}$ & P value \\
\hline Variable & $\begin{array}{l}\text { Average } \\
\text { ( } \pm \text { standard } \\
\text { deviation) / } \\
\text { frequency (\%) }\end{array}$ & & & & \\
\hline \multicolumn{6}{|l|}{ Gender } \\
\hline Male & 803 (59.39\%) & $258(55.72)$ & $188(60.84)$ & $355(61.21)$ & \multirow[t]{2}{*}{0.16} \\
\hline Female & 549 (40.6\%) & 205 (44.28) & $121(39.16)$ & 225 (38.79) & \\
\hline Age & $47 \pm 16.19$ & $49.39 \pm 15.12$ & $48.15 \pm 15.7$ & $44.61 \pm 16.93$ & 0.21 \\
\hline Weight & $70.17 \pm 19.77$ & $72.17 \pm 21.38$ & $68.79 \pm 17.64$ & $69.27 \pm 21.21$ & 0.11 \\
\hline \multicolumn{6}{|l|}{ Nationality } \\
\hline Arab & 690 (51.04\%) & $237(51.19)$ & $166(53.72)$ & $286(49.31)$ & \multirow[t]{4}{*}{0.17} \\
\hline Asian (non-Arab) & 567 (41.94\%) & 194 (41.9) & $114(36.89)$ & $258(44.48)$ & \\
\hline $\begin{array}{l}\text { African (non- } \\
\text { Arab) }\end{array}$ & $36(2.66 \%)$ & $10(2.16)$ & $14(4.53)$ & $12(2.07)$ & \\
\hline Others & 59 (4.36\%) & $22(4.75)$ & $15(4.85)$ & $24(4.14)$ & \\
\hline \multicolumn{6}{|l|}{ Ward type } \\
\hline Oncology & $994(73.52 \%)$ & $358(77.32)$ & $176(56.96)$ & $460(79.31)$ & 0.003 \\
\hline
\end{tabular}




\begin{tabular}{|l|l|l|l|l|}
\hline Hematology & $207(15.31 \%)$ & $67(14.47)$ & $65(21.04)$ & $62(10.69)$ \\
\hline Palliative care & $149(11.02 \%)$ & $36(7.78)$ & $65(21.04)$ & $47(8.1)$ \\
\hline Critical care & $2(0.15 \%)$ & $2(0.43)$ & $3(0.97)$ & $11(1.9)$ \\
\hline
\end{tabular}

419 Table 2. Added cost, cost saving, and cost avoidance for clinical pharmacist intervention types.

\begin{tabular}{|c|c|c|c|}
\hline Type of interventions & $\begin{array}{l}\text { Overall added cost } \\
\text { with interventions, } \\
\text { QAR (USD) }\end{array}$ & $\begin{array}{l}\text { Overall saving, } \\
\text { QAR (USD) }\end{array}$ & $\begin{array}{l}\text { Overall cost avoidance, } \\
\text { QAR (USD) }\end{array}$ \\
\hline Addition of another medication & $1,560,419(428,569)$ & 0 & $35,052,450(9,627,148)$ \\
\hline Discontinuation of a medication & $109,924(30,191)$ & $23,807(6,539)$ & $45,025,307(12,366,192)$ \\
\hline Switching to alternative medication & $206,805(56,799)$ & $190,799(52,403)$ & $18,202,132(4,999,212)$ \\
\hline $\begin{array}{l}\text { Addition of a prophylactic agent } \\
\text { during hospitalization }\end{array}$ & $599,698(164,707)$ & 0 & $31,875,257(8,754,533)$ \\
\hline Change in medication route & $156(43)$ & $16,732(4,595)$ & $2,421,641(665,103)$ \\
\hline Change in medication strength & 0 & $2,488(683)$ & $47,357(13,007)$ \\
\hline Therapeutic drug monitoring & $900(247)$ & 0 & $5,191,999(1,425,981)$ \\
\hline Change in medication dose & $9,568(2,628)$ & $13,890(3,815)$ & $13,302,882(3,653,634)$ \\
\hline Change in medication duration & $4,589(1,260)$ & $2,162(594)$ & $4,378,328(1,202,507)$ \\
\hline Change in medication frequency & $765(210)$ & $6,036(1,658)$ & $6,091,773(1,673,104)$ \\
\hline Addition of a lab test & $4,286(1,177)$ & 0 & $13,957,264(3,833,360)$ \\
\hline Addition of a diagnostic test & $1,638(450)$ & 0 & $1,571,376(431,578)$ \\
\hline
\end{tabular}




\begin{tabular}{|l|l|l|l|}
\hline Addition of a culture test & $480(132)$ & 0 & $968,657(266,041)$ \\
\hline Addition of a vaccine & 0 & 0 & 0 \\
\hline
\end{tabular}

*QAR: Qatari Riyal, USD: United States Dollar

421

422 Table 3. Outcomes of cost-benefit analysis

\begin{tabular}{|l|l|}
\hline Outcome & Value, QAR (USD) \\
\hline Salary of the clinical pharmacists per 3 months & $180,000(49,437)$ \\
\hline months & \\
\hline Overall cost of intervention per 3 months & $1,125,500(309,118)$ \\
\hline Overall cost saving per 3 months & $1,245,826(342,166)$ \\
\hline Overall cost avoidance per 3 months & $194,764,534(53,492,040)$ \\
\hline Net benefit per 3-month & $194,884,860(53,525,088)$ \\
\hline Net benefit per 1-year & $779,539,440(214,100,351)$ \\
\hline Benefit-to-cost ratio & $174: 1$ \\
\hline Total benefit per 3 months & $196,010,360(53,834,206)$ \\
\hline${ }^{*}$ QAR: Qatari Riyal, USD: United States Dollar & \\
\hline
\end{tabular}

424

425

426

427 
429 Table 4. Uncertainty distributions used for one-way and probabilistic sensitivity analysis, and their 430 outcomes

\begin{tabular}{|c|c|c|c|c|c|}
\hline Variable & $\begin{array}{l}\text { Point } \\
\text { estimate, } \\
\text { QAR (USD) }\end{array}$ & $\begin{array}{l}\text { Variation range, QAR } \\
\text { (USD) }\end{array}$ & $\begin{array}{l}\text { Net benefit per } 1 \\
\text { year range, QAR } \\
\text { (USD) }\end{array}$ & $\begin{array}{l}\text { Benefit to } \\
\text { cost ratio }\end{array}$ & $\begin{array}{l}\text { Total benefit per } \\
\text { 3-month, QAR } \\
\text { (USD) }\end{array}$ \\
\hline \multicolumn{6}{|c|}{ One-way sensitivity analysis } \\
\hline $\begin{array}{l}\text { Salary of clinical } \\
\text { pharmacist }\end{array}$ & $\begin{array}{l}30,000 \\
(8,239)\end{array}$ & $\begin{array}{l}\text { Triangular distribution } \\
\text { (QAR } \\
24,000,30,000,36,000 \text { ) } \\
\text { (USD 6,592, 8,239, } \\
9,887 \text { ) }\end{array}$ & $\begin{array}{l}\text { Mean: } \\
779,539,440 \\
\text { (USD } \\
214,100,351) \text {, } \\
95 \% \mathrm{Cl} \\
779,401,581 \text { to } \\
779,678,323 \\
(U S D \\
214,062,488 \text { to } \\
214,138,495)\end{array}$ & $\begin{array}{l}\text { Mean: } 174 \text {, } \\
95 \% \mathrm{Cl} 169 \\
\text { to } 180\end{array}$ & $\begin{array}{l}\text { Mean: } \\
196,011,842 \\
\text { (USD } \\
53,834,613 \text { ), } 95 \% \\
\text { CI 157,971,465 to } \\
234,026,797 \\
\text { (USD 43,386,831 } \\
\text { to } 64,275,413 \text { ) }\end{array}$ \\
\hline $\begin{array}{l}\text { Cost of adverse drug } \\
\text { event }\end{array}$ & $\begin{array}{l}9,359 \\
(2,570)\end{array}$ & $\begin{array}{l}\text { Triangular distribution } \\
\text { (QAR } \\
8,423,9,359,10,295 \text { ) } \\
\text { (USD 2313, 2,570, } \\
2,828 \text { ) }\end{array}$ & $\begin{array}{l}\text { Mean: } \\
779,552,059 \\
\text { (USD } \\
214,103,817 \text { ), } \\
95 \% \mathrm{Cl} \\
626,969,446 \text { to } \\
934,425,777\end{array}$ & $\begin{array}{l}\text { Mean: } 174 \text {, } \\
95 \% \mathrm{Cl} 141 \\
\text { to } 208\end{array}$ & $\begin{array}{l}\text { Mean: } \\
196,008,409 \\
\text { (USD } \\
53,833,670 \text { ), } 95 \% \\
\text { Cl 158,165,714 to } \\
233,236,517 \text { (USD }\end{array}$ \\
\hline
\end{tabular}




\begin{tabular}{|c|c|c|c|c|c|}
\hline & & & $\begin{array}{l}\text { (USD } \\
172,197,033 \text { to } \\
256,639,853)\end{array}$ & & $\begin{array}{l}43,440,182 \text { to } \\
64,058,363)\end{array}$ \\
\hline \multicolumn{6}{|c|}{ Multivariate uncertainty analysis } \\
\hline $\begin{array}{l}\text { Very low probability } \\
\text { for ADE }\end{array}$ & 0.03 & $\begin{array}{l}\text { Triangular distribution } \\
(0.025,0.03,0.035)\end{array}$ & $\begin{array}{l}\text { Mean: } \\
843,766,754\end{array}$ & $\begin{array}{l}\text { Mean: } 188, \\
95 \% \mathrm{Cl} 155\end{array}$ & $\begin{array}{l}\text { Mean: } \\
\text { 212,096,666 (USD }\end{array}$ \\
\hline $\begin{array}{l}\text { Low probability for } \\
\text { ADE }\end{array}$ & 0.1 & $\begin{array}{l}\text { Triangular distribution } \\
(0.09,0.1,0.11)\end{array}$ & $\begin{array}{l}\text { (USD } \\
231,740,370)\end{array}$ & to 231 & $\begin{array}{l}58,252,30), 95 \% \\
\text { Cl } 171,962,981 \text { to }\end{array}$ \\
\hline $\begin{array}{l}\text { Low to moderate } \\
\text { probability for ADE }\end{array}$ & 0.2 & $\begin{array}{l}\text { Triangular distribution } \\
(0.17,0.2,0.23)\end{array}$ & $\begin{array}{l}95 \% \mathrm{Cl} \\
838,336,934 \text { to }\end{array}$ & & $\begin{array}{l}257,301,517 \text { (USD } \\
47,229,598 \text { to }\end{array}$ \\
\hline $\begin{array}{l}\text { Low to moderate } \\
\text { probability for ADE }\end{array}$ & 0.3 & $\begin{array}{l}\text { Triangular distribution } \\
(0.26,0.3,0.35)\end{array}$ & $\begin{array}{l}848,401,062 \\
\text { (USD }\end{array}$ & & $70,667,810)$ \\
\hline $\begin{array}{l}\text { Moderate } \\
\text { probability for ADE }\end{array}$ & 0.4 & $\begin{array}{l}\text { Triangular distribution } \\
(0.35,0.4,0.46)\end{array}$ & $\begin{array}{l}230,249,071 \text { to } \\
233,013,182)\end{array}$ & & \\
\hline $\begin{array}{l}\text { Moderate to high } \\
\text { probability for ADE }\end{array}$ & 0.5 & $\begin{array}{l}\text { Triangular distribution } \\
(0.43,0.5,0.58)\end{array}$ & & & \\
\hline
\end{tabular}

432

433

434

435

436 
439 None.

$440 \quad$ Funding

441 This work was supported by Medical Research Center, Hamad Medical Corporation [grant number (MRC-

442 01-19-110)].

\section{Competing Interests}

444 The authors have no relevant financial or non-financial conflicting interests to disclose.

445

446 Author Contributions

447 DA contributed to the study conception and design, data validation, data analysis and interpretation, and 448 wrote the first draft of manuscript. DB led the study conception and design, and contributed to data 449 analysis and interpretation. AG contributed to the data collection. AH, PA, MA, WE, and ME facilitated the 450 planning and carrying out of the study. All authors contributed to the final version of manuscript.

452 Ethics approval

453 This study was performed in line with the principles of the Declaration of Helsinki. Approval was granted 454 by the Medical Research Center, Hamad Medical Corporation (MRC-01-19-110).

455 Consent to participate

$456 \quad$ None. 


\section{Supplementary Files}

This is a list of supplementary files associated with this preprint. Click to download.

- SupplementarylnformationS1.pdf

- SupplementarylnformationS2.pdf

- SupplementarylnformationS3.pdf 